\title{
Sexual function after anterior urethroplasty: a systematic review
}

\author{
Paola Calleja Hermosa ${ }^{1} \wedge$, Felix Campos-Juanatey ${ }^{1,2}$, Raquel Varea Malo ${ }^{1 \wedge}$, \\ Miguel Ángel Correas Gómez ${ }^{1,3}$, Jose Luis Gutiérrez Baños ${ }^{1,3}$; Trauma and Reconstructive Urology \\ Working Party of the European Association of Urology Young Academic Urologists
}

${ }^{1}$ Urology Department, Marques de Valdecilla University Hospital, Santander, Spain; ${ }^{2}$ Valdecilla Research Institute (IDIVAL), Santander, Spain; ${ }^{3}$ Medical and Surgical Sciences Department, School of Medicine, University of Cantabria, Santander, Spain

Contributions: (I) Conception and design: P Calleja Hermosa, F Campos-Juanatey; (II) Administrative support: MÁ Correas Gómez, JL Gutiérrez Baños; (III) Provision of study materials or patients: P Calleja Hermosa, F Campos-Juanatey; (IV) Collection and assembly of data: P Calleja Hermosa, F Campos-Juanatey, R Varea Malo; (V) Data analysis and interpretation: P Calleja Hermosa, F Campos-Juanatey; (VI) Manuscript writing: All authors; (VII) Final approval of manuscript: All authors.

Correspondence to: Felix Campos-Juanatey. Avenida Valdecilla 25, 39008. Santander, Spain. Email: felix.campos@scsalud.es.

Background: Urethral surgery outcomes are often evaluated by assessing urinary flow and urethral patency. However, sexual consequences may appear after urethroplasty, impairing quality of life and patient's perception of success.

The aim of this study is to assess the relationship between anterior urethral reconstruction and postoperative sexual dysfunction, including the proposed factors predicting sexual outcomes.

Methods: We searched in PubMed database using the terms: "anterior urethroplasty", bulbar urethroplasty" or "penile urethroplasty", and "sexual dysfunction", "erectile function" or "ejaculation". Articles were independently evaluated for inclusion based on predetermined criteria. Systematic data extraction was followed by a comprehensive summary of evidence.

Results: Thirty-eight studies were included for final analysis. No randomised trial on the topic was found. Urethral surgery might affect different aspects of sexual function: erectile function, ejaculatory function, penile shape and length, and genital sensitivity, leading to severe sexual dysfunction. Patient perception of sexual impairment was related to post-operative satisfaction.

Conclusions: Sexual dysfunction after anterior urethral reconstruction is an important issue that must be appropriately discussed during preoperative patient counselling. Reported outcomes after anterior urethroplasty should include sexual consequences and relevance, evaluated using validated tools.

Keywords: Urethra; stricture; urethroplasty; sexual function; erectile dysfunction (ED)

Submitted Oct 02, 2020. Accepted for publication Jan 27, 2021.

doi: $10.21037 /$ tau-20-1307

View this article at: http://dx.doi.org/10.21037/tau-20-1307

\section{Introduction}

Urethral stricture has an estimated prevalence of 229-627 cases per 100,000 males ( $0.6 \%$ of susceptible populations in the United States) (1). According to recent European studies, urethral stricture disease affects men of all ages, with a mean age at diagnosis of 46 years (range, $1-85$ years) $(2,3)$. Urethroplasty is the most definitive treatment for anterior urethral strictures, reaching successful outcomes in up to $98 \%$ of patients (4).

In the urethral reconstruction field, the concept

^ ORCID: Paola Calleja Hermosa, 0000-0003-0494-5346; Felix Campos-Juanatey, 0000-0002-2231-5199; Raquel Varea Malo, 0000-00016519-4801; Jose Luis Gutiérrez Baños, 0000-0002-6461-1172. 
of success was historically defined as the avoidance of secondary procedures. Recently, interest has shifted towards patient satisfaction. Patient-reported outcome measures (PROMs) have been developed for addressing both micturition and sexual function (5).

Any sexual dysfunction (SD) or genital complication related to urethral reconstruction could impact quality of life, and patient satisfaction after surgery, even if the procedure is considered "successful" and a patent urethra is achieved. These aspects must be considered and discussed at the time of preoperative patient counselling.

The aim of the present review is to summarize the impact of male anterior urethral reconstruction over postoperative sexual function, including erectile function, ejaculation, penile size, penile curvature, and genital sensitivity. Possible factors predicting sexual outcomes were additionally discussed. We present the following article in accordance with the PRISMA checklist (available at: http:// dx.doi.org/10.21037/tau-20-1307).

\section{Methods}

The Preferred Reporting Items for Systematic Reviews and Meta-Analyses (PRISMA) statement criteria were followed for our review (6). The inclusion and exclusion criteria were determined prior to the literature search.

PubMed database was searched using the terms: "anterior urethroplasty", "bulbar urethroplasty" or "penile urethroplasty", and "sexual dysfunction", "erectile function" or "ejaculation". A detailed search of further relevant literature was conducted in the bibliography of the selected papers.

The eligibility criteria included English-language studies, on male patients older than 18 years old, who underwent any type of anterior urethroplasty. No publication year restrictions were applied.

Case reports with less than 10 patients were excluded. We also excluded studies focused on posterior urethroplasty, pelvic fracture related urethral injuries, primary hypospadias repair, or permanent perineal urethrostomy.

Our initial search found 141 articles (Figure 1). The titles and abstracts were screened by two independent authors and 48 articles were selected for potential inclusion. An additional 14 articles were included from searching the references of the selected articles. Full text articles were retrieved for all selected references. After independent review, articles were excluded if they did not meet inclusion criteria or did not contain relevant information on the topic.
In case of disagreement, a third reviewer would decide whether the study should be included.

Finally, 38 articles were included. Data extraction was done independently by two reviewers. Information extracted from the selected articles included:

* Study dates,

* Prospective or retrospective study design;

* Mono or multicentric study;

* Number of patients;

* Location of the strictures;

* Mean stricture length;

* Type of urethroplasties performed;

* Length of follow-up;

* Percentage of patients with de novo ED after urethroplasty;

* Whether a standardized questionnaire was used to assess ED;

* Whether or not patients were questioned about erectile function (EF) before their operation;

* Whether patients were questioned about ejaculatory function and whether a standardized questionnaire on ejaculation was used;

* Whether penile curvature, or shortening was evaluated;

* Whether cold glans and penile sensitivity was evaluated;

* Whether patient satisfaction was specifically evaluated.

\section{Results}

\section{Evaluation of SD}

SD after urethroplasty includes several disorders related to the sexual health that may arise after urethral repair such as erectile dysfunction (ED), ejaculation dysfunction (EjD), penile curvature, penile shortening, or genital sensitivity disorders.

Mundy et al. were the first to report ED after urethroplasty in 1993 . They described a $5 \%$ permanent ED after anastomotic urethroplasty (AU) and $0.9 \%$ after patch urethroplasty in a series of 200 patients (7). After their report, numerous other studies have assessed the topic.

According to a metanalysis by Blaschko et al. in 2013, the reported incidence of ED after urethroplasty is $1 \%$, however, available data are heterogeneous, ranging from $0 \%$ to $40 \%$ of postoperative SD (8). In fact, it is difficult to compare results among different studies as they evaluate 


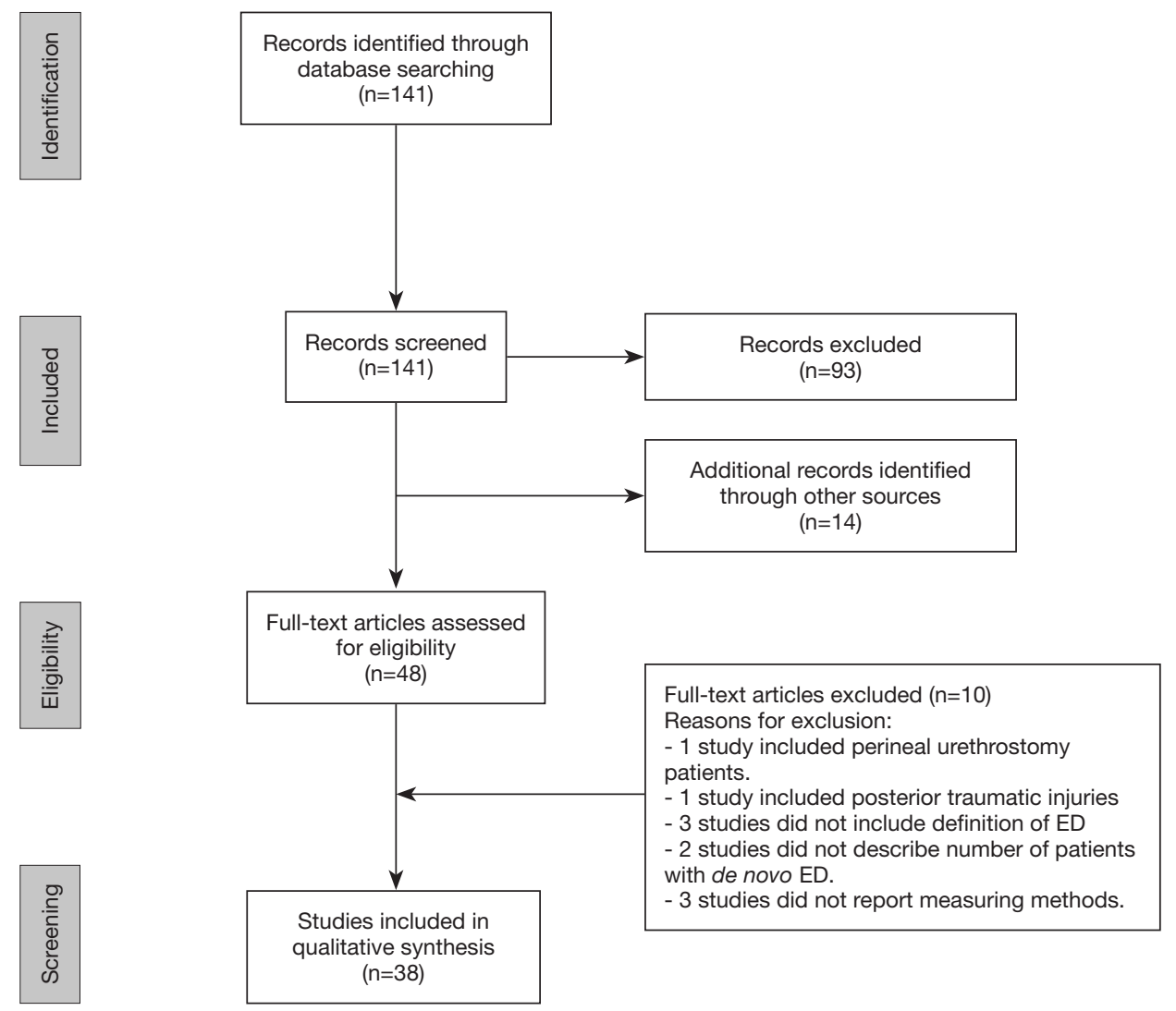

Figure 1 PRISMA flow diagram. ED, erectile dysfunction.

patients using different tools. Over the years, published reports have changed from direct questions about sexual problems towards a more objective assessment of SD, using validated questionnaires and including a preoperative assessment of baseline sexual function.

Below, we describe the most frequent questionnaires used to evaluate SD. However, none of these questionnaires are specific for post-urethroplasty patients.

* International Index of Erectile Function (IIEF) (9): validated self-administered 15 -items questionnaire evaluating 4 domains: erectile function (Q1-5, Q15), orgasmic function (Q9-10), sexual desire (Q11-12), intercourse satisfaction (Q6-8) and overall satisfaction (Q13-14). Each question is answered in a $0-5$ scale, to a maximum of 75 points.

* Sexual Health Inventory for Men (SHIM or IIEF5): modified 5-item version of the IIEF, designed to assess the presence and severity of ED according to specified benchmarks.

* O’Leary Brief Male Sexual Function Inventory (BMSFI) (10): a 11-question questionnaire that rates from $0-4$ the following items: sexual drive, $\mathrm{EF}$, ejaculation, problem assessment and overall satisfaction. There are no defined benchmarks for this questionnaire, so it is difficult to state the clinical relevance of a certain decline.

- Male Sexual Health Questionnaire (MSHQ) (11): 25 -item self-administered questionnaire that evaluates erection, ejaculation, and satisfaction. Some authors used ejaculation items as an independent questionnaire, as it provides a detailed evaluation of the topic (MSHQ-EjD).

Palminteri et al. laid emphasis in the importance of preoperative counselling (12) for patients, especially regarding the sexual health consequences of surgeries. In a study evaluating the outcomes of ventral buccal mucosa graft (BMG) urethroplasty, $73 \%$ of patients declared a medium/high anxiety degree tackling urethroplasty, and $27 \%$ denied having been adequately informed regarding possible sexual complications after their surgeries. Regarding the most relevant fears before undergoing urethroplasty, $85 \%$ declared being afraid that surgery might 
not resolve their problem, $35 \%$ said they were afraid of a postoperative worsening in the quality of sexual life and $31 \%$ reported to be afraid of postoperative genital scars.

\section{ED after anterior uretbroplasty}

\section{Aetiology of ED}

De novo ED after anterior urethral repair may have a neurogenic or vascular origin due to:

* Injury to the bulbar arteries or cavernosalspongiosal branches during mobilization or transection of the bulbar urethra.

* Injury to the cavernous nerves during intercrural dissection of the urethra. These nerves run at 1 and 11 o'clock positions close to the proximal bulbar urethra (13).

* Injury of the perineal nerve; it rises from the pudendal nerve at the ischiorectal fossa and travels alongside the ischiocavernous and bulbospongiosus muscles (14). It extends branches that innervate the bulbospongiosus muscle, and contributes to innervation of corpus spongiosum, which may be important in erection, although the mechanism is unclear. The perineal nerve continues on the ventral side of penis giving sensory branches to innervate the ventral side of the penis, including the frenular area.

* Interaction between perineal nerves and penile dorsal nerves was observed by Yucel and Baskin (15), suggesting this interaction may be responsible for some unexplained neural reflexes causing erection, orgasm and ejaculation.

Psychosomatic factors may also play a role in the onset of ED. Coursey et al. (16) found that $27.3 \%$ of the patients related worsened erections after circumcision in otherwise healthy controls. They suggest that alterations in penile appearance could affect short-term sexual performance.

\section{Predictive factors for ED after anterior urethroplasty}

Factors such as age, stricture location, length of stricture and procedure have been proposed to affect sexual function after urethroplasty.

\section{Age at the time of the urethroplasty}

Erickson et al. (17) used BMSFI to evaluate SD after urethral reconstruction. They found that patients older than 50 years, experienced a significant decline in mean EF domain, contrary to younger patients.

Likewise, Anger et al. (18) suggested that age and preoperative EF may adversely affect postoperative sexual outcome. In their prospective review, men with a postoperative score $\leq 20$ in EF domain of IIEF questionnaire were older (mean age 47 vs. 36.8 years, $\mathrm{P}=0.17$ ) and had worse preoperative $\mathrm{EF}$ values (mean 20 vs. 29, $\mathrm{P}=0.11$ ) than those with postoperative EF scores $>20$, although the differences did not attain statistical significance.

Other authors did not find any association between age and occurrence of ED (19-21), although data showed that older men had lower preoperative IIEF scores and a greater decline in IIEF values $(19,22)$. On multivariate analysis, Chapman et al. (21) did not find an association between age and SD.

\section{Length of stricture}

Coursey et al. (16) proposed length of stricture as a predictive factor, as they reported men with worse postoperative EF having a significantly longer stricture than those with improved or unchanged erection (mean 6.8 vs. $4 \mathrm{~cm}$ ). However, further studies contradict this association $(17,21,23)$.

\section{Location of stricture}

In a subanalysis of men with normal preoperative EF, Erickson et al. (24) revealed an overall postoperative ED of $66 \%$, corresponding to bulbar repairs in $16(76 \%)$ cases and to penile urethroplasties in $3(38 \%)$. It is important to note that all but 2 men returned to their baseline EF after a median of 6 months.

Pfalzgraf et al. (25) did not find statistically significant differences between penile and bulbar groups regarding EF median score (26.5 vs. 14; $\mathrm{P}=0.47$ ) or intercourse satisfaction median score ( 9.5 vs. $0 ; \mathrm{P}=0.13$ ). However, a difference between groups can be suspected. The size of the cohort could explain the difficulty to demonstrate statistical significance.

In contrast, Haines et al. (22) reported that stricture location was not associated with change in EF when examining both incidence of adverse change (defined as a change in IIEF-EF domain $\geq 5)(20.3 \%$ vs. $21.7 \%$; $\mathrm{P}=1.0)$ and mean change $(+0.95 v s .-2.74 ; \mathrm{P}=0.18)$.

\section{Erectile function after different surgical techniques}

Penile strictures can be managed by flap or graft urethroplasties. Over the years, grafting has been the choice for penile repair, with a reported ED between 4-19\% (16,19), although it was transient in most cases. In the case of penile flaps, Coursey et al. (16) reported $40 \%$ of worsened postoperative $\mathrm{EF}$ in their series of 44 patients.

Although AU are mostly used in bulbar urethra, Shakir et al. (26) stated that AU has a high success rate and good 
sexual outcomes in short strictures in the pendulous urethra, especially in traumatic origin. In their small series, all patients reported stable EF, with median postoperative IIEF5 score of 21 (IQR: 19-25) after a median follow up of 43 months.

Staged urethroplasty with BMG offers high success rates for patients with complex penile strictures. However, sexual outcomes in this specific population are scarce. Patel et al. (27) reported a median SHIM postoperative score of 23 (IQR: 19-25) in these patients. No significant SHIM score difference from preoperative baseline was found at a median follow-up of 6.3 months after second stage surgery. Only 1 (4\%) patient required ED medications postoperatively.

Bulbar strictures can be managed by anastomotic techniques - with or without complete transection of the corpus spongiosum- or augmentation urethroplasties, most frequently using BMG. The consequences over the sexual function of these two different approaches have been extensively discussed.

The excision and primary anastomosis technique (EPA) is characterised by complete transection of the urethra and extensive mobilization of bulbar segment in order to accomplish a tension free anastomosis. It is normally indicated for short obliterative strictures. However, some authors have challenged the indication for longer strictures. Morey et al. (28) presented a series of 22 men who underwent EPA for short $(\leq 2.5 \mathrm{~cm})$ or long strictures $(>2.5 \mathrm{~cm})$. An EF questionnaire was administered at 6 months postoperatively. Men in the longer stricture group had no increased rate of stricture recurrence or erectile complaints compared to men with shorter strictures. Complete loss of erections was reported in 2 patients from short stricture group and in none of $>2.5 \mathrm{~cm}$.

Barbagli et al. (29) investigated postoperative sexual disorders associated with bulbar EPA through a nonvalidated questionnaire administered by phone calls in 60 patients. Most of them had a stricture $<3 \mathrm{~cm}(97.4 \%)$. No patient complained of de novo ED.

D'Hulst et al. (30) used IIEF5 to assess EF in 23 sexually active patients who underwent EPA. Patients were evaluated at 3 different times postoperatively. Fifteen patients with mild or no baseline ED (IIEF5 >17) had a significant decline in EF at 3 months follow-up (IIEF5: 23.27 vs. 13.91; $\mathrm{P}=0.002)$. This impairment remained significant at 6 months but was recovered by 18 months (23.25). Patients with moderate to severe ED (IIEF5 <16) at baseline experienced no significant difference in EF at any time point.
In an effort to avoid injuries to bulbar vessels during EPA, non-transecting techniques were developed. The original idea of a vessel sparing technique in AU was described by Jordan et al. in 2007 (31), specifically dissecting bulbar arteries off the urethra to preserve them. Later, Andrich and Mundy (32) described the non-transecting anastomotic bulbar urethroplasty (ntAU). Contrary to Jordan's technique, they avoid dissecting the bulb of corpus spongiosum from the perineal body. The ntAU is based in a dorsal stricturotomy, excision of urethral stricture with surrounding spongiofibrosis, but leaving healthy ventral spongiosum intact. The ventral aspect is then sutured and dorsal stricturotomy is transversely closed.

Since the description of both techniques, some authors have compared classic EPA with new non-transecting modifications, presenting contradictory data. Haines et al. failed to find statistical differences between transecting and non-transecting groups regarding EF (22). Chapman et al. (21) retrospectively compared 94 non-transecting urethroplasties vs. $258 \mathrm{EPA}$, with a mean follow-up of 64.2 months. De novo $\mathrm{SD}$ appeared more frequently in EPA cohort than in the nontransecting cohort ( $14.3 \%$ vs. $4.3 \%$, respectively; $\mathrm{P}=0.008)$. On multivariate analysis, urethral transection was the only factor associated with $\mathrm{SD}(\mathrm{P}=0.01)$.

Lumen et al. (33) proposed a ventral stricturoplasty, following the Heineke-Mikulicz principle. The indication of this technique is restricted to short $(\leq 1 \mathrm{~cm})$, not too narrow strictures in bulbar urethra or fossa navicularis. They used a non-validated questionnaire to assess SF. None of 9 patients who were sexually active (6 with bulbar strictures) reported ejaculatory disturbances, ED, or diminished penile sensitivity.

Grafting techniques are usually indicated in longer bulbar strictures $(>2-3 \mathrm{~cm})$ and may benefit from maintaining the urethral vasculature intact.

Palminteri et al. (12) reported the impact of ventral BMG urethroplasty on sexual life of 52 patients, using MSHQ and their unvalidated Post-Urethroplasty Sexual Questionnaire (PUSQ), 1 year postoperatively. No patient complained of worsened erection, whereas 18 (35\%) of them reported better erections. This improvement is probably related to an amelioration of quality of life. The same group (34) also described a two-sided bulbar urethroplasty using dorsal plus ventral BMG. They developed this technique for tight bulbar strictures. None of 49 sexually active men reported impaired erection compared to preoperative status. Moreover, EF improvement was reported by 7 patients (14\%).

Spencer et al. (35) evaluated the consequences of dorsal 
BMG onlay technique described by Kulkarni et al. for strictures longer than $8 \mathrm{~cm}$. They found no significant difference in preoperative and postoperative SHIM score (19.7 vs. 18.1; $\mathrm{P}=0.17$ ). Most patients demonstrated no change in IIEF5 score $(67 \%)$ or even an improvement of $\geq 4$ points (14.3\%). However, $21.4 \%$ of patients reported a reduction of $\geq 4$ points in SHIM score.

Several authors have evaluated whether grafting techniques are superior to transecting bulbar urethroplasty regarding $\mathrm{SF}$ outcomes.

Kessler et al. (36) evaluated 267 patients who underwent surgical repair of urethral strictures. As there were no validated questionnaires on urethral stricture at the time, they designed a non-validated questionnaire to assess voiding, sexual function, and satisfaction. The patients were assessed after a median 37 months from the surgery. In the EPA group, $79 \%$ of 39 patients reported moderate to severe erection impairment, whereas in BMG group only $15 \%$ of 29 patients demonstrated such deterioration. Of those treated with BMG, $81 \%$ reported none or little impairment in sexual life, while in $43 \%$ of EPA, sexual life was severely impaired.

Beysens et al. (37) compared AU (31 cases) with free graft urethroplasty (16 cases). They evidenced a significant decline in IIEF5 score after 6 weeks in AU group (-4.8; $\mathrm{P}=0.005)$ but not in a free graft cohort $(+0.9 ; \mathrm{P}=0.115)$. After 6 months, there were no longer significant changes in IIEF5 score in any of the groups.

Erickson et al. (24) reported that men undergoing EPA had higher postoperative ED rates than those submitted to augmented anastomotic repairs (AAR) $(50 \%$ vs. $26 \%$, $\mathrm{P}=0.16)$. This high postoperative $\mathrm{ED}$ rates are recognised early in postoperative period (mean 2 months) but are mostly transient, with only 2 men reporting persistent ED after a median follow-up of 6 months.

Dogra et al. (19) reported a postoperative ED rate of $28 \%$ for EPA, and $10 \%$ for BMG urethroplasties. However, recovery of $\mathrm{EF}$ was seen in $96 \%$ on men, and only 3 patients from EPA group continued to have ED at the end of this study (mean follow-up 5.6 months).

Furr et al. (38) reported sexual results of their cohort of bulbar urethroplasties using EPA (96 patients) vs. dorsal BMG urethroplasty (32 patients). There were no significant differences between groups regarding IIEF5 postoperative score (BMG 18.4 vs. EPA 17.1), patients with IIEF5 >15 (BMG 69\% vs. EPA 69\%), potency or difficulty achieving erections (BMG 31\% vs. EPA 27\%).

In summary, there is no consensus whether anastomotic techniques affect ED more than grafting techniques. Results are largely variable, with ED reported rates between 0-79\% in EPA and $0-26 \%$ in augmentation urethroplasties. Indeed, these studies are difficult to compare because of different assessment or different time moments. It seems that in most cases early postoperative ED may be transient: 6 studies reported resolution of ED between 6-20 months after surgery $(17,19,23,24,30,37)$. Non-transecting techniques seem to diminish vascular damage secondary to EPA repairs, but their clinical benefit over EF is yet to be consistently proven (see Table 1 for details). There is an ongoing prospective, multi-center, randomized, non-inferiority trial, comparing transecting and non-transecting techniques (46). This study will provide evidence on both surgical and functional results after these techniques, including erectile function, and will try to shed light on the value of bulbar artery preservation.

\section{Ejaculatory dysfunction after anterior uretbroplasty}

Changes in ejaculatory function after bulbar urethroplasty EjD can be already present before urethroplasty. Urethral obstruction may cause impact on ejaculatory function itself. Preoperative reported prevalence is wide, ranging from 0 to $85 \%$. According to Erickson et al. (47), $25 \%$ of patients reported poor preoperative ejaculatory function. The most common related problems were poor ejaculatory volume $(100 \%)$, vigor $(91 \%)$ and pain with ejaculation (100\%). Palminteri et al. (12) also described preoperative ejaculatory disorders related to bulbar strictures in a prospective study of 52 men. The patients reported reduced ejaculatory stream (85\%), painful ejaculations (27\%), and ejaculation failures $(27 \%)$. These and others sexual disorders had influenced quality of life in $46 \%$ of the patients.

Most studies reported improved ejaculatory function after restoration of urethral lumen. However, sometimes EjD persisted or even worsened. This may be explained by bulbospongiosus muscle (BSM) division during bulbar urethroplasty, or by perineal nerve damage. BSM is known to have an important role in semen emission and probably in urine expelling too, avoiding urine sequestration in the urethral bulb. The perineal nerve can be damaged during dissection of the central tendon of perineum, when it is emerging from ischiorectal fossa or, when BSM is fully divided along its midline, causing both sensitivity deficiencies and possibly ejaculatory disorders.

Barbagli et al. (29) retrospectively studied the sexual consequences of bulbar EPA with a non-validated telephone 


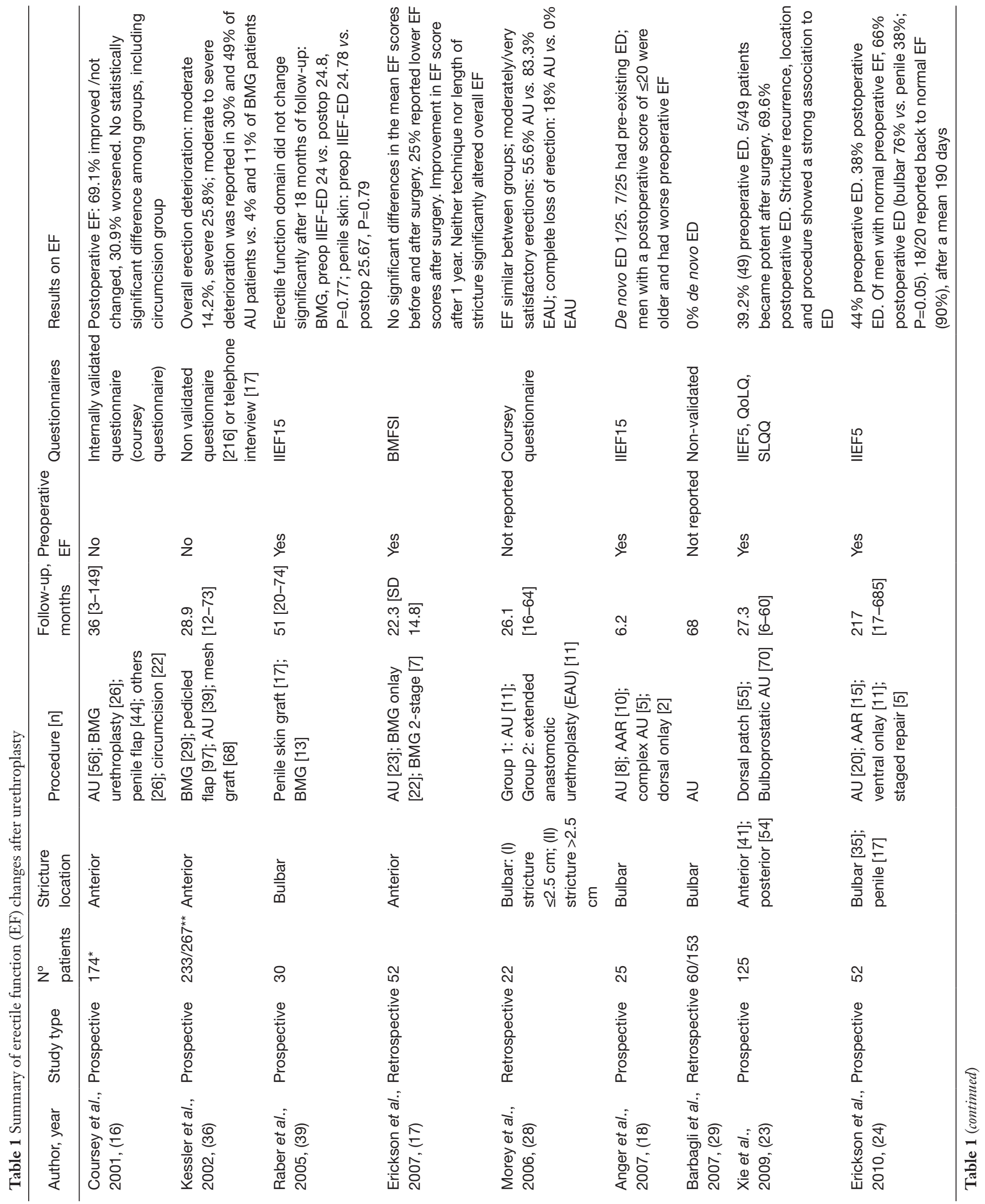




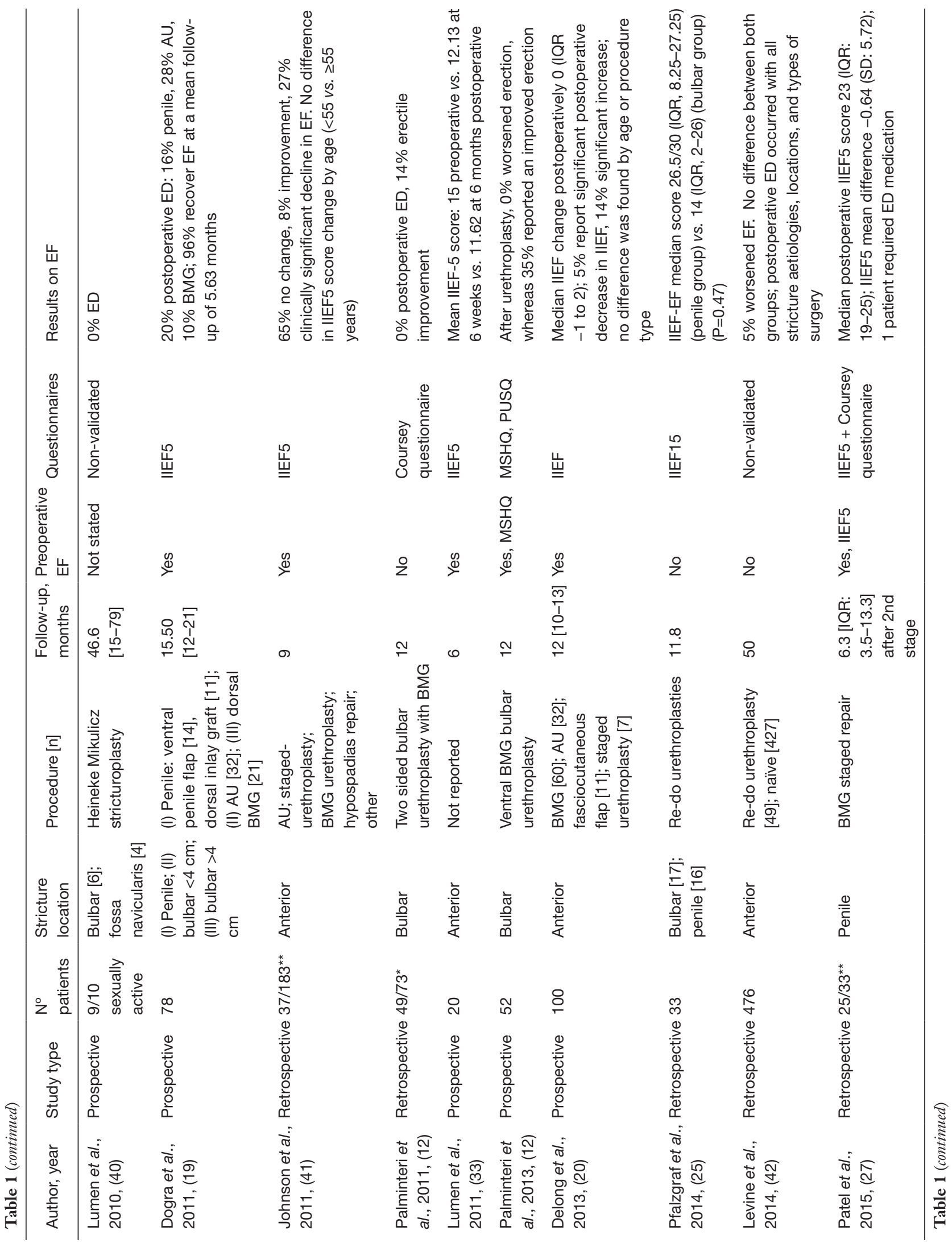




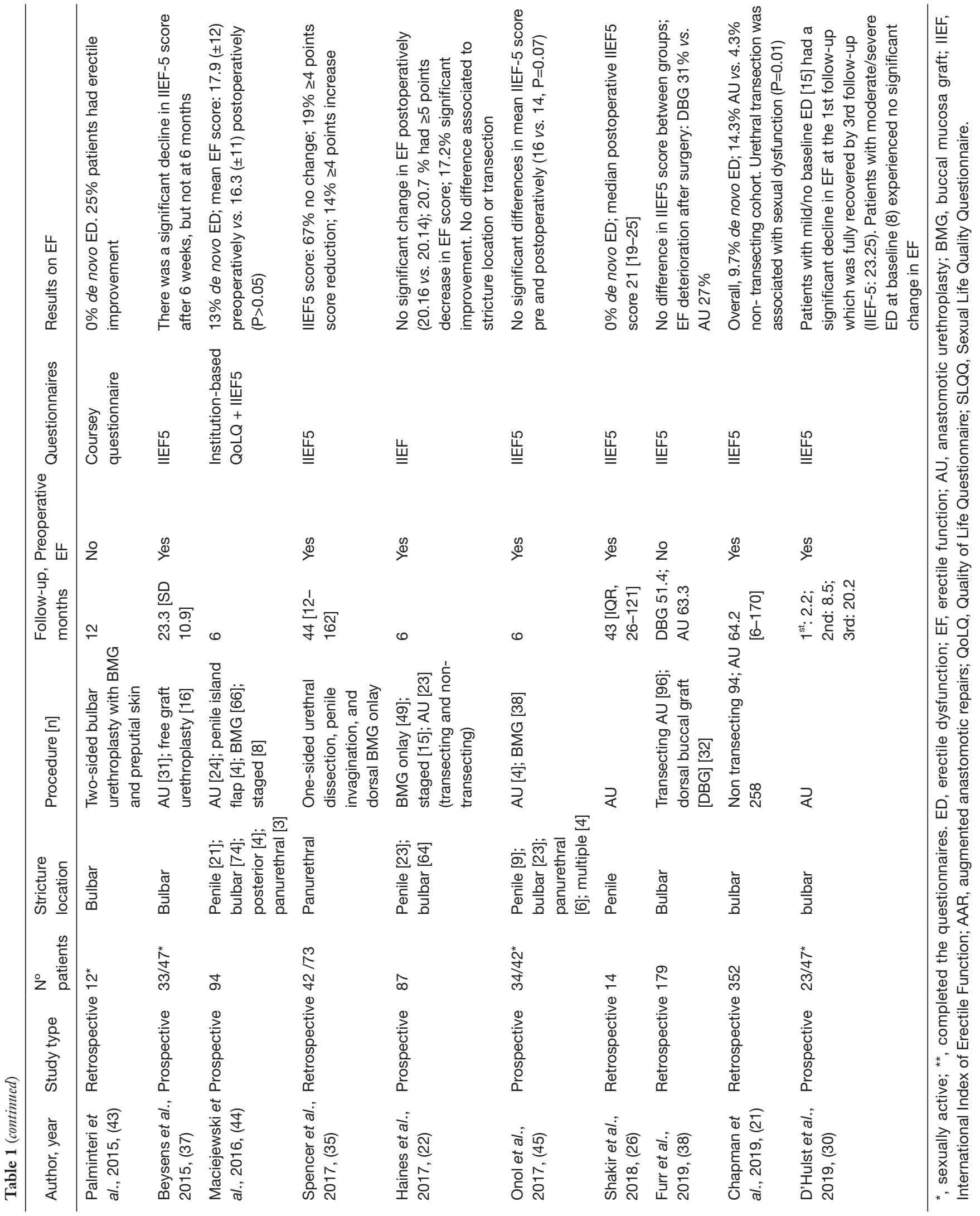


questionnaire. $20 \%$ of patients experienced decreased ejaculation force and $3.3 \%$ of the patients reported semen sequestration in urethral bulb. According to the hypothesis that $\mathrm{EjD}$ is secondary to BSM division or perineal nerve damage, they developed a BSM-sparing bulbar urethroplasty technique (48). They report a series of 12 patients with bulbar urethroplasty preserving bulbospongiosus muscle, central tendon of perineum, and perineal nerves. No patient showed decreased force of semen emission nor postvoiding dribbling at 6 and 12 months after surgery.

Later, Fredrick et al. (49) designed a comparative study to evaluate the effects of BSM sparing during bulbar urethroplasty. Patients were assessed pre- and postoperatively with MSHQ as well as a patient perception questionnaire. They found no significant differences between BSM sparing and non-sparing groups in mean post-operative MSHQ score or MSHQ score change. Their findings failed to demonstrate any short-term differences in post-operative ejaculatory function by preserving BSM. When broken down by EPA vs. graft, there was no significant difference in perception of ejaculation between BSM-sparing and non-sparing groups.

Ejaculation dysfunction could also be related to outpouching and diverticulum formation after ventral substitution techniques. Dubey et al. (50) presented a series of urethral strictures repaired either with skin flap or free graft. Patients with ventral flap/graft onlay urethroplasty reported a higher incidence of $\mathrm{EjD}(20 \%)$, in the form of scanty ejaculation, compared to dorsal onlay $(5 \% ; \mathrm{P}=0.03)$. They corroborated the presence of flap out-pouching during follow-up in $26 \%$ of ventral onlay urethroplasties $v s$. $3 \%$ of dorsal onlay $(\mathrm{P}=0.01)$.

This data contrasts those of Palminteri et al. (12). They evaluated ejaculatory function with both MSHQ-LF and PUSQ questionnaires in their series of ventral BMG bulbar urethroplasty. After surgery, most of their patients had an improved ejaculation (65\%) in terms of force, volume, and pleasure. They showed post-urethroplasty improvement both in total MSHQ score and in each of the principal domains, including ejaculation score, ejaculation bother score, sexual activity, and desire score. Only $19 \%$ of the patients reported worsened ejaculation because of postejaculation dribbling or reduced stream.

Even in longer strictures, ejaculatory function seems to improve in most cases after urethroplasty. Spencer et al. (35) analysed this aspect in 25 patients with strictures $>8 \mathrm{~cm}$ treated by dorsal $\mathrm{BMG}$ onlay technique, using both preand post-operative MSHQ-EjD questionnaires. MSHQ-EjS scores had improved from 8 (range, 4-13) preoperatively to 11 (range, $4-15)$ postoperatively $(\mathrm{P}=0.0004)$. Seventy-six percent of the patients reported improved ejaculation, $16 \%$ reported worsened ejaculation, and $8 \%$ had no change.

Erickson et al. (47) designed a prospective study evaluating EjD in 43 sexually active patients through MSHQ-EjS questionnaire prior and after urethroplasty. They reported stable ejaculatory function in $70 \%$ of the men, increased in $19 \%$, and decreased in only $11 \%$. No significant changes were found in overall ejaculatory scores at a median follow-up of 6.8 months. On subanalysis, men with poor preoperative ejaculatory function had a significantly improved score postoperatively. Likewise, significant amelioration was seen in most MSHQ ejaculatory categories. Mean stricture length in patients reporting decreased ejaculatory function was $4.1 \pm 1.1 \mathrm{~cm}$, not significantly different from men with stable or improved ejaculation $(\mathrm{P}=0.81)$. No patient with normal ejaculatory function preoperatively had significantly decreased function after urethroplasty nor had recurrent strictures during the study period.

Again, AU and augmentation techniques have been largely compared, but they do not seem to differ regarding postoperative ejaculatory function. Beysens et al. (37) prospectively compared AU or grafting for bulbar strictures. EPA was preferred whenever a tension-free anastomosis could be made (stricture length $<3 \mathrm{~cm}$ ); for longer strictures, augmentation was performed. Thirty-seven patients filled the Ejaculatory/Orgasm Score (EOS) questionnaire prior and after surgery (23 EPA vs. 14 graft augmentation). EOS is calculated from the sum of questions 9 and 10 from IIEF, and it ranges from 2 (no ejaculation/orgasm) to 10 (normal). Although overall there was no significant postoperative change in EOS; patients in EPA group had a transient significant decline in EOS score at 6 weeks $(-1.4 ; \mathrm{P}=0.022)$ which returned to baseline at 6 months $(-0.4 ; \mathrm{P}=0.431)$.

Furr et al. (38) compared EPA -selected for shorter $(<3 \mathrm{~cm})$, more proximal bulbar strictures-with dorsal BMG urethroplasty - typically reserved for longer strictures $(>3-3.5 \mathrm{~cm})$ or those located in distal bulbar urethra. They found no differences between groups in terms of postoperative MSHQ-EJD ejaculatory score or bother.

\section{Changes in ejaculatory function after penile urethroplasty}

The TURNS Group (27) reviewed ejaculation after staged penile urethroplasty in 57 patients. Only 20 patients filled in preoperative and postoperative MSHQ-EjD questionnaires. 
There was no statistically significant difference in scores before and after penile urethroplasty. Mean difference in pre- and postoperative MSHQ score was 1.55 ( $\mathrm{SD}=6.57$ ). For question 4 on the MSHQ-EjD, $40 \%$ reported reduced $\mathrm{EjD}$ bother, and $45 \%$ reported no change. This data may be biased by the reduced questionnaire completion rate (35\%).

\section{Changes in ejaculatory function after revision urethroplasty}

Ejaculation function after re-do urethroplasties was assessed by Pfalzgraf et al. (25). When asked about ejaculation after surgery, $63.6 \%$ of patients reported normal ejaculatory function, while $15.2 \%$ and $3 \%$ reported a slight or a severe decrease in ejaculation strength, respectively. No differences between bulbar and penile strictures were found in this aspect.

In summary, patients may already present EjD secondary to urethral lumen obstruction previous to urethroplasty. Urethral repairs improve ejaculatory function in most cases, but it may worsen in $0-20 \%$ of the patients (see Table 2 for details). According to Palminteri et al. (12), some manoeuvres can be implemented to reduce the risk of ejaculatory disorders:

* Careful midline opening of bulbospongiosus muscle;

* Avoiding damaging of the nerve branches positioned more laterally;

* No division of perineal central tendon that takes part in the ejaculatory mechanism;

* Good coverage of the graft with corpus spongiosum;

* Reconstructing the bulbospongiosus muscle.

\section{Penile shortening and curvature}

Penile length loss and penile curvature are potential complications after urethral reconstruction, and depending on their degree, they can severely impair sexual life and be a cause of patient's dissatisfaction with urethroplasty outcomes (36).

\section{Penile shortening and curvature after urethroplasty in the bulbar urethra}

Coursey et al. (16) assessed the change in penile angulation and shortening through a non-validated questionnaire after anterior urethroplasty. Most patients reported no change in penile angulation. Those patients who noticed an altered erectile angle or penile length had a significantly longer

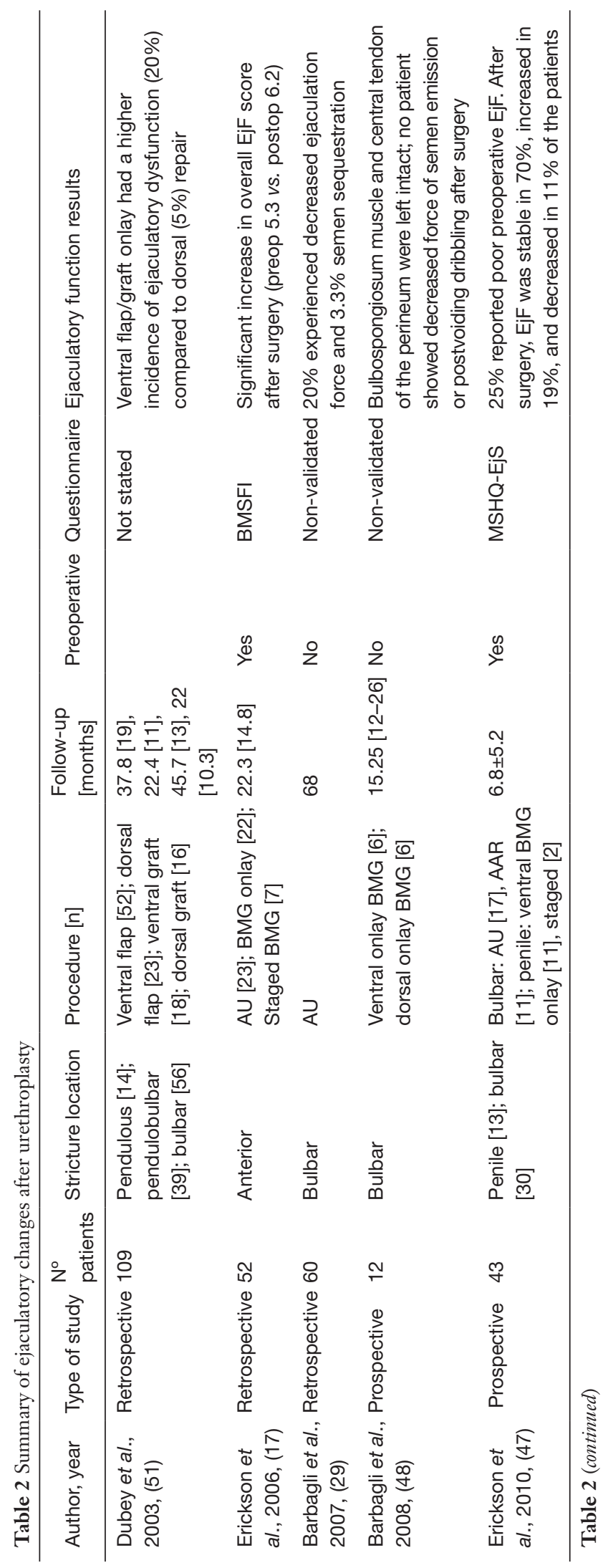




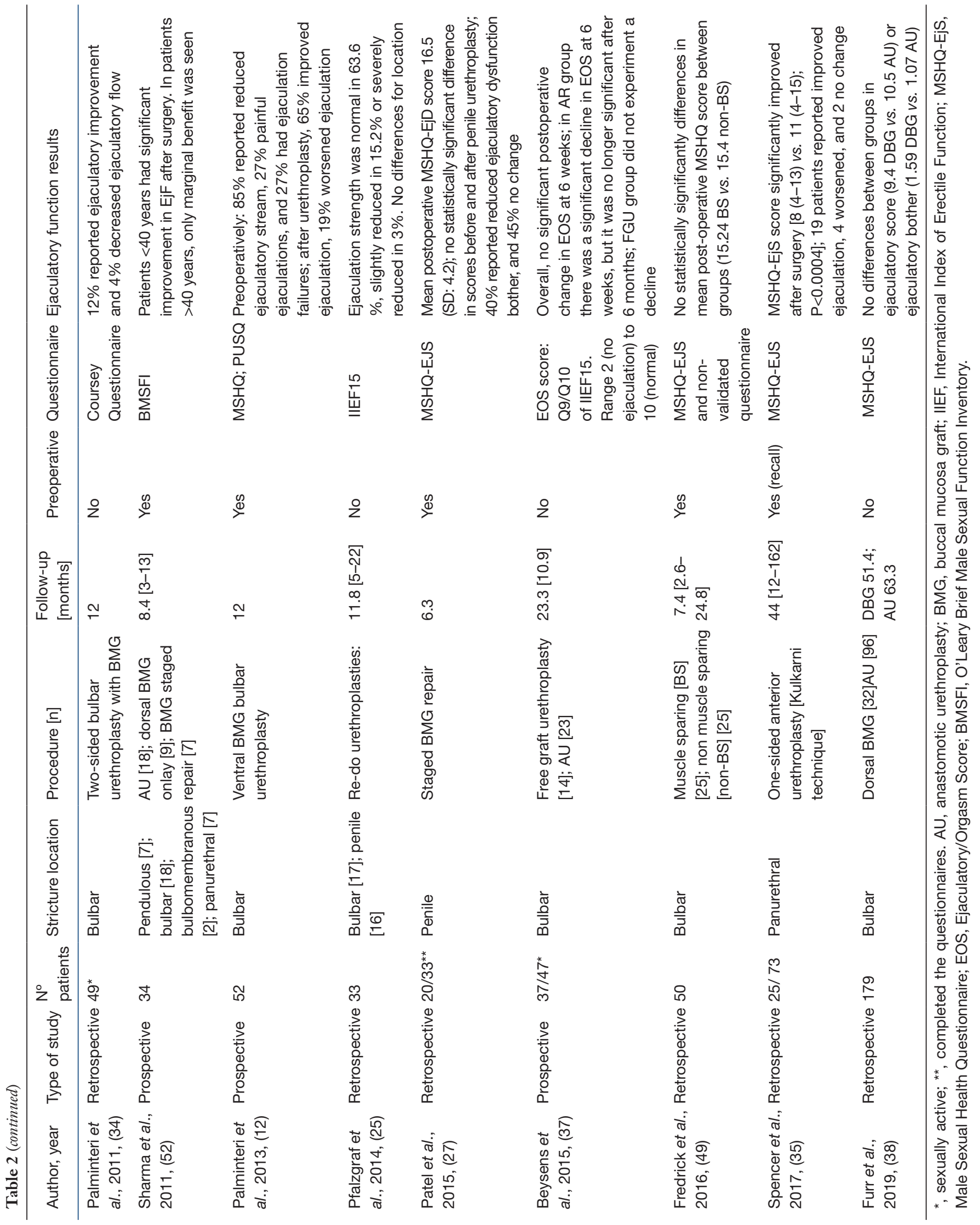


stricture than those who did not $(\mathrm{P}=0.05)$. A "major change" in erect angle was reported in $8.9 \% \mathrm{AU}$ and $7.7 \% \mathrm{BMG}$ urethroplasties. However, most patients reported that it improved over time.

Kessler et al. (36) assessed a series of 225 patients after different anterior urethroplasties. In this study, patients reported none/little, moderate or severe curvature in $74.7 \%, 15.1 \%$ and $10.2 \%$ respectively.

EPA was associated with a higher proportion of severe penile shortening $(30 \%)$ compared with the overall severe shortening (15.6\%). The EPA group suffered moderate or severe curvature in $22 \%$ and $14 \%$ of cases respectively, while BMG urethroplasty group declared a $4 \%$ moderate and $4 \%$ severe postoperative penile curvature. None of BMG urethroplasty patients reported severe shortening. Although AU is a successful treatment, the increased risk of penile shortening and chordee has led to the thought of reserving this procedure for short bulbar strictures $(<3 \mathrm{~cm})$. Following this principle, Barbagli et al. (29) used EPA in 153 patients of which $91(59.5 \%)$ had strictures $<2 \mathrm{~cm}$ and $58(37.9 \%)$ strictures ranging from 2 to $3 \mathrm{~cm}$, using this technique in only 4 patients (2.6\%) with strictures longer than $3 \mathrm{~cm}$. No patient complained of penile chordee or ED.

Morey et al. (28) compared anastomotic repair in strictures shorter (group 1) or longer than $2.5 \mathrm{~cm}$ (group 2). Surprisingly, $44.4 \%$ of patients in group 1 reported some penile angulation and $22 \%$ a mild decrease of penile length, while $0 \%$ and $33 \%$ of the patients in group 2 reported penile angulation or mild shortening, respectively.

Regarding the use of substitution techniques, Palminteri et al. (12) reported that $8 \%$ of the patients developed "a little" curvature after ventral BMG urethroplasty, and 4\% "a little" shortening, with no patient reporting severe changes. In their series of 2-sided bulbar urethroplasty with BMG (34), none of the patients reported penile length loss or postoperative curvature.

Furr et al. (38) compares the results of EPA versus dorsal BMG urethroplasty in a series of 179 patients. Tethering with erections was significantly more frequent with EPA (23.4\%) vs. BMG (3.1\%). However, $76 \%$ of patients who experienced tethering reported completely satisfactory sexual activity.

\section{Penile shortening and curvature after urethroplasty for penobulbar strictures}

Long panurethral strictures repair may imply higher risk of penile shortening and chordee. Kulkarni et al. (53) developed a technique including 1-sided urethral dissection, penile invagination and dorsal BMG onlay, that attempts to minimize over-mobilization or excision of the urethra. It is mandatory to keep the penis stretched during the procedure to allow loose graft fixation. Spencer et al. (35) report their sexual outcomes using this technique in a cohort with a mean stricture length of $13.6 \mathrm{~cm}(8-21 \mathrm{~cm})$. They found $25 \%$ of patients with chordee. Curvature was transient and resolved by the first year in 13/18 men (72\%); however, 2 patients required surgical correction using a dorsal plication technique.

\section{Penile shortening and curvature after urethroplasty in the penile urethra}

Anastomotic repair is normally avoided in penile stricture. However, Shakir et al. (26) presented a series of 14 focal penile strictures-median length $1.0 \mathrm{~cm}$ (IQR. 1.0-1.4)-repaired with EPA. No patients reported de novo penile curvature or penile shortening postoperatively.

Regarding different techniques in penile strictures, Coursey et al. (16) assessed penile flap urethroplasty resulted in slightly more penile shortening and erectile angle alteration $(18.9 \%)$ than other procedures $(\mathrm{P}=0.05)$.

The TURNS group (27) evaluated staged penile urethroplasties using BMG. They report new penile curvature in $23 \%$ of the patients. Also, when questioned, $10 \%$ patients complained of "quite a bit a loss" in penile length while $45 \%$ stated "somewhat of a loss".

\section{Penile shortening and curvature after revision urethroplasty}

Two studies specifically address re-do urethroplasties. Levine et al. (54) found that the incidence of chordee was higher in the re-do group (14.3\%) compared to primary urethroplasties (2.7\%). Pfalzgraf et al. (25) found an overall penile curvature of $15.2 \%$. No patient reported a strong deviation, but all patients complaining of moderate chordee (18.8\%) underwent previous penile urethroplasties. Describing length loss, any penile shortening was reported by $17.6 \%$ of bulbar urethroplasty patients compared with $37.6 \%$ of those operated in the penile urethra. Severe length loss was a consequence of $5.9 \%$ and $6.3 \%$ of bulbar and penile urethroplasties, respectively.

A common limitation to all the studies is the subjective nature of the reports. None of the retrieved literature included objective measurement of the degree of curvature or penile length loss, neither the authors described how severity was categorized. This heterogeneity makes it exceedingly difficult to compare reported outcomes. 
Table 3 Summary of penile length loss after urethroplasty

\begin{tabular}{|c|c|c|c|c|c|c|}
\hline Author, year & Study type & $\begin{array}{l}\mathrm{N}^{\circ} \\
\text { patients }\end{array}$ & Stricture location & Procedure & $\begin{array}{l}\text { Follow-up } \\
\text { (months) }\end{array}$ & Results \\
\hline $\begin{array}{l}\text { Coursey et al., } \\
2001,(16)\end{array}$ & Prospective & $174^{*}$ & Anterior & $\begin{array}{l}\text { AU [56]; BMG urethroplasty } \\
\text { [26]; penile flap [44]; others } \\
\text { [26]; circumcision [22] }\end{array}$ & 36 [3-149] & $\begin{array}{l}\text { Major change in erect length: } \\
27.3 \% \text { penile flap; } 10.7 \% \text { AU; } \\
\text { 15.4\% BMG; } 11.5 \% \text { others; } \\
22.7 \% \text { circumcision; patients } \\
\text { with change in penile length } \\
\text { had a significantly longer } \\
\text { stricture }(P=0.05)\end{array}$ \\
\hline $\begin{array}{l}\text { Kessler et al., } \\
2002,(36)\end{array}$ & Prospective & $233 / 267^{\text {** }}$ & Anterior & $\begin{array}{l}\text { BMG [29]; pedicled flap [97]; } \\
\text { AU [39]; mesh graft [68] }\end{array}$ & $\begin{array}{l}28.9 \\
{[12-73]}\end{array}$ & $\begin{array}{l}\text { Overall: } 15,6 \% \text { severe penile } \\
\text { shortening; marked or severe } \\
\text { penile shortening: 0\% BMG, } \\
11 \% \text { flap, } 30 \% \text { AU, } 21 \% \text { mesh } \\
\text { graft }\end{array}$ \\
\hline
\end{tabular}

\begin{tabular}{|c|c|c|c|c|c|c|}
\hline $\begin{array}{l}\text { AL Qudah } \\
\text { et al., 2005, (55) }\end{array}$ & Retrospective & 60 & $\begin{array}{l}\text { Prostatomembranous } \\
\text { [1]; membranobulbar } \\
\text { [8]; bulbar [41]; penile } \\
\text { [12] }\end{array}$ & $\begin{array}{l}\text { AU [24]; ventral onlay BMG } \\
\text { [19]; onlay flap [10]; posterior } \\
\text { AU [9] }\end{array}$ & 29 [10-53] & $\begin{array}{l}1 \text { patient who underwent onlay } \\
\text { flap reported shortening }\end{array}$ \\
\hline $\begin{array}{l}\text { Morey et al., } \\
2006,(28)\end{array}$ & Retrospective & 22 & $\begin{array}{l}\text { Bulbar: group } 1[11] \text {, } \\
\text { stricture } \leq 2.5 \mathrm{~cm} \text {; } \\
\text { group } 2 \text { [11]: stricture } \\
>2.5 \mathrm{~cm}\end{array}$ & $\begin{array}{l}\text { Group 1: AU; Group 2: } \\
\text { extended anastomotic } \\
\text { urethroplasty }\end{array}$ & $\begin{array}{l}26.1 \\
{[16-64]}\end{array}$ & $\begin{array}{l}\text { Mild, persistent shortening } \\
33.3 \% \text { group } 2 \text { vs. } 22.2 \% \text { in } \\
\text { group } 1(P=0.4), 0 \% \text { severe } \\
\text { shortening }\end{array}$ \\
\hline $\begin{array}{l}\text { Palminteri } \\
\text { et al., 2011, (34) }\end{array}$ & Retrospective & $49 / 73^{*}$ & Bulbar & $\begin{array}{l}\text { Two sided bulbar } \\
\text { urethroplasty with BMG }\end{array}$ & 12 & $0 \%$ penile shortening \\
\hline $\begin{array}{l}\text { Palminteri } \\
\text { et al., 2013, (12) }\end{array}$ & Prospective & 52 & Bulbar & $\begin{array}{l}\text { Ventral BMG bulbar } \\
\text { urethroplasty }\end{array}$ & 12 & $\begin{array}{l}4 \% \text { a little shortening; } 0 \% \\
\text { marked shortening }\end{array}$ \\
\hline $\begin{array}{l}\text { Pfalzgraf et al., } \\
2014,(25)\end{array}$ & Retrospective & 33 & $\begin{array}{l}\text { Bulbar [17]; penile } \\
{[16]}\end{array}$ & Re-do urethroplasties & 11.8 & $\begin{array}{l}\text { Overall: } 9.1 \% \text { reported } \\
\text { moderate shortening and } \\
6.1 \% \text { severe length loss: } \\
\text { Bulbar: moderate } 11.8 \% \text {, } \\
\text { severe } 5.9 \% \text {; penile: moderate } \\
6.3 \% \text {, severe } 6.3 \%\end{array}$ \\
\hline $\begin{array}{l}\text { Patel et al., } \\
2015,(27)\end{array}$ & Retrospective & $22 / 33^{\star *}$ & Penile & BMG staged repair & - & $\begin{array}{l}10 \% \text { "quite a bit a loss" in } \\
\text { penile length; } 45 \% \text { "somewhat } \\
\text { of a loss" }\end{array}$ \\
\hline $\begin{array}{l}\text { Palminteri } \\
\text { et al., 2015, (43) }\end{array}$ & Retrospective & $12^{*}$ & Bulbar & $\begin{array}{l}\text { Two sided bulbar urethroplasty } \\
\text { with BMG and preputial skin }\end{array}$ & 12 & $0 \%$ penile shortening \\
\hline $\begin{array}{l}\text { Shakir et al., } \\
2018,(26)\end{array}$ & Retrospective & 14 & Penile & $A U$ & $\begin{array}{l}43 \text { [IQR, } \\
26-121]\end{array}$ & $0 \%$ penile shortening \\
\hline
\end{tabular}

${ }^{*}$, sexually active; ${ }^{\star \star}$, completed the questionnaires. AU, anastomotic urethroplasty; BMG, buccal mucosa graft.

Anastomotic techniques are thought to have an increased risk of penile curvature and shortening compared to other techniques. Such risk increases with stricture length and penile involvement, and also when revision surgeries are required. However, the available data are scarce, and further and objective investigations are needed in the topic (see Tables 3,4 for details).

\section{Cold glans sensation and decreased penile sensitivity}

Patients may refer incomplete glans tumescence and genital area sensitivity changes after urethroplasty. These undesirable consequences could interfere with sexual satisfaction. Cold glans is traditionally attributed to the transection of corpus spongiosum for primary anastomosis, 
Table 4 Summary of penile curvature after urethroplasty

\begin{tabular}{|c|c|c|c|c|c|c|}
\hline Author, year & Study type & $\begin{array}{l}\mathrm{N}^{\circ} \\
\text { patients }\end{array}$ & Stricture location & Procedure [n] & $\begin{array}{l}\text { Follow-up } \\
\text { (months) }\end{array}$ & Results \\
\hline $\begin{array}{l}\text { Coursey et al., } \\
2001,(16)\end{array}$ & Prospective & $174^{*}$ & Anterior & $\begin{array}{l}\text { AU [56]; BMG } \\
\text { urethroplasty [26]; penile } \\
\text { flap [44]; others [26]; } \\
\text { circumcision [22] }\end{array}$ & $\begin{array}{l}36 \text { (range, } \\
3-149)\end{array}$ & $\begin{array}{l}\text { Major change in erect angle: } 8.9 \% \\
\text { AU; } 7.7 \% \text { BMG; } 18.2 \% \text { penile flap; } \\
23.1 \% \text { other; } 9.5 \% \text { circumcision }\end{array}$ \\
\hline $\begin{array}{l}\text { Kessler et al., } \\
2002,(36)\end{array}$ & Prospective & $233 / 267^{\star *}$ & Anterior & $\begin{array}{l}\text { BMG [29]; pedicled flap } \\
\text { [97]; AU [39]; mesh graft } \\
\text { [68] }\end{array}$ & $\begin{array}{l}28.9 \\
{[12-73]}\end{array}$ & $\begin{array}{l}\text { Severe chordee: overall } 10.2 \% \text {; by } \\
\text { procedure, } 4 \% \text { BMG, } 5 \% \text { flap, } 14 \\
\% \text { AU, } 18 \% \text { mesh graft }\end{array}$ \\
\hline $\begin{array}{l}\text { AL Qudah et } \\
\text { al., 2005, (55) }\end{array}$ & Retrospective & 60 & $\begin{array}{l}\text { Prostatomembranous [1]; } \\
\text { membrano-bulbar [8]; } \\
\text { bulbar [41]; penile [12] }\end{array}$ & $\begin{array}{l}\text { AU [24]; ventral onlay } \\
\text { BMG [19]; onlay flap [10]; } \\
\text { posterior AU [9] }\end{array}$ & 29 [10-53] & $\begin{array}{l}\text { Chordee was reported in } 4 \% \text { AU; } \\
0 \% \text { BMG; } 20 \% \text { onlay flap; } 11 \% \\
\text { posterior }\end{array}$ \\
\hline $\begin{array}{l}\text { Morey et al., } \\
2006,(28)\end{array}$ & Retrospective & 22 & $\begin{array}{l}\text { Bulbar: group } 1[11], \leq 2.5 \\
\mathrm{~cm} ; \text { group } 2[11]:>2.5 \mathrm{~cm}\end{array}$ & $\begin{array}{l}\text { Group 1: AU; Group 2: } \\
\text { extended AU }\end{array}$ & $\begin{array}{l}26.1 \\
{[16-64]}\end{array}$ & $\begin{array}{l}44.4 \% \text { in group } 1 \text { noticed some } \\
\text { angulation, } 0 \% \text { in group } 2\end{array}$ \\
\hline $\begin{array}{l}\text { Palminteri et } \\
\text { al., 2011, (34) }\end{array}$ & Retrospective & $49 / 73^{*}$ & Bulbar & $\begin{array}{l}\text { Two sided bulbar } \\
\text { urethroplasty with BMG }\end{array}$ & 12 & $0 \%$ postoperative penile curvature \\
\hline $\begin{array}{l}\text { Palminteri et } \\
\text { al., 2013, (12) }\end{array}$ & Prospective & 52 & Bulbar & $\begin{array}{l}\text { Ventral BMG bulbar } \\
\text { urethroplasty }\end{array}$ & 12 & $\begin{array}{l}8 \% \text { "a little" curvature, } 0 \% \text { marked } \\
\text { curvature }\end{array}$ \\
\hline $\begin{array}{l}\text { Pfalzgraf et al., } \\
2014,(25)\end{array}$ & Retrospective & 33 & Bulbar [17]; penile [16] & Re-do urethroplasties & 11.8 & $\begin{array}{l}\text { Penile curvature was more } \\
\text { frequently reported after penile } \\
\text { urethroplasty ( } 25.1 \% \text { vs. } 5.9 \% \text { in } \\
\text { bulbar urethroplasty) }\end{array}$ \\
\hline $\begin{array}{l}\text { Levine et al., } \\
2014,(42)\end{array}$ & Retrospective & 476 & Anterior & Re-do 49; naïve 427 & 50 & $\begin{array}{l}\text { Chordee in } 2.7 \% \text { naïve vs. } 14.3 \% \\
\text { re-do; } \mathrm{P}<0.01\end{array}$ \\
\hline $\begin{array}{l}\text { Spencer et al., } \\
2017,(35)\end{array}$ & Retrospective & $42 / 73$ & Panurethral & $\begin{array}{l}\text { 1-sided urethral } \\
\text { dissection, penile } \\
\text { invagination, dorsal } \\
\text { BMG onlay [Kulkarni } \\
\text { technique] }\end{array}$ & $\begin{array}{l}44 \\
{[12-162]}\end{array}$ & $\begin{array}{l}25 \% \text { chordee. This was transient } \\
\text { and resolved by the first year in } \\
72 \% \text { of the patients; however, } \\
2 \text { patients required surgical } \\
\text { correction }\end{array}$ \\
\hline $\begin{array}{l}\text { Shakir et al., } \\
2018,(26)\end{array}$ & Retrospective & 14 & Penile & $A U$ & $\begin{array}{l}43 \text { (IQR, } \\
26-121)\end{array}$ & $0 \%$ postoperative curvature \\
\hline $\begin{array}{l}\text { Furr et al., } \\
2019,(38)\end{array}$ & Retrospective & 179 & Bulbar & $\begin{array}{l}\text { Transecting AU [96]; } \\
\text { dorsal BMG [DBG] [32] }\end{array}$ & $\begin{array}{l}\text { DBG } 51.4 ; \\
\text { AU } 63.3\end{array}$ & $\begin{array}{l}\text { Chordee reported in } 23.4 \% \text { AU } \\
\text { vs. } 3.1 \% \text { DBG }(P=0.008) .76 \% \\
\text { of patients who experienced } \\
\text { tethering reported completely } \\
\text { satisfactory sexual activity }\end{array}$ \\
\hline
\end{tabular}

*, sexually active; ${ }^{\star *}$, completed the questionnaires. AU, anastomotic urethroplasty; BMG, buccal mucosa graft; DBG, dorsal buccal grafting. 
which may lead to poor distal blood flow and consequently, impaired glans tumescence. Genital sensitivity disorders could be triggered by injuries to perineal nerve branches during bulbar urethral dissection.

In a cohort of patients evaluated after EPA for bulbar stricture, Barbagli et al. (29) reported $1.6 \%$ of them complaining of cold glans during erection, and $11.6 \%$ of poor glans tumescence. Also 18.3\% described decreased sensitivity of the glans or distal penile shaft. However only the patient with cold glans reported dissatisfaction with the outcomes of surgery for this reason (1.6\%).

After ventral BMG bulbar urethroplasty, Palminteri et al. (12) reported $42 \%$ of patients describing changes in sensitivity in scrotum or perineum, and $4 \%$ complaining of cold glans (all of them had a completely engorged glans). Conversely, none of the patients presented problems in their sexual activity because of these sensitivity disorders.

Beysens et al. (37) compared the results of anastomotic repair versus grafting urethroplasty-using prepuce (12 patients) and BMG (4 patients). They evaluated patients at 6 weeks and 6 months postoperatively, using a non-validated questionnaire containing 3 dichotomous questions about glans tumescence, alterations in genital sensitivity, and cold feeling in the glans. Further analysis of glans tumescence was only done in patients reporting normal EF (IIEF5 $\geq 20$ ) in order to avoid contamination due to globally diminished penile tumescence. At 6 weeks, $62.2 \%$ reported to have altered genital sensitivity, without significant differences between groups. At 6 months, 52\% still reported altered genital sensitivity. Only one patient, treated by AU, had a cold feeling in the glans, who no longer reported this feeling at 6 months. Of 20 patients with IIEF $5 \geq 20$ at 6 weeks, $10 \% \mathrm{AU}$ and $40 \%$ augmentation patients reported no glans tumescence $(\mathrm{P}=0.303)$. At 6 months, $16.7 \%$ (1 of 6 patients) $\mathrm{AU}$ and $60 \%$ (3 out of 5 ) augmentation patients, reported no glans tumescence $(\mathrm{P}=0.242)$. Although changes in genital sensitivity were not significantly different among subgroups, it is remarkable that augmentation urethroplasty patients reported a higher rate of sensitivity changes at 6 weeks (66.7\% vs. $53.3 \%$ in AU group). The authors attribute these early changes to the use of preputial skin graft in most of these patients. However, even after 6 months, changes in genital sensitivity were still frequently reported, and this also occurred in patients treated with BMG.

In another comparison of EPA $v s$. dorsal graft urethroplasty, Furr et al. (38) reported decreased glans filling in $10.6 \%$ and $9.4 \%$ of patients, respectively. They also found decreased penile sensation in $23.4 \%$ and $18.8 \%$ of EPA and grafting cohorts. Only $5.2 \%$ of EPA patients complained of cold glans, with none in the augmentation group $(\mathrm{P}=0.19)$. However, despite of cold glans, 4 of 5 patients reported satisfactory sexual intercourse.

After re-do urethroplasties in penile (16 cases) and bulbar (17 cases) areas, Pfalzgraf et al. (25) described nondisturbing alteration in glans sensitivity in $24.2 \%$ of the patients. In addition, 9.1\% reported this alteration as disturbing. Glans sensitivity was more frequently impaired after penile urethroplasty $(\mathrm{P}=0.03)$. These authors hypothesize that the found difference is probably due to more extensive urethral mobilization in penile urethroplasty.

In summary, cold glans is described by $0-5 \%$ of patients after urethroplasty. Decreased glans tumescence is highly variable, ranging from $0 \%$ to $60 \%$ in grafting series and between $10 \%$ to $16 \%$ in anastomotic series. Genital altered sensitivity is reported in $10 \%$ to $50 \%$ of patients. However, what is really important is how these alterations affect patient's sexual life and satisfaction with their urethroplasty, as some of studies $(12,29,38)$ stated that patients maintained a satisfactory sexual life regardless of presenting such disorders (see Table 5 for details).

\section{Relevance of sexual bealth complications in satisfaction after anterior uretbroplasty}

Some authors have addressed specifically how postoperative sexual changes affect patient satisfaction after urethroplasty.

Bertrand et al. (56) examined patient reported satisfaction following anterior urethroplasty. Men reporting satisfactory outcomes had higher postoperative SHIM scores (19.2 vs. 16.1, $\mathrm{P}<0.01)$, less change in postoperative SHIM scores (-0.04 vs. $-3.2, \mathrm{P}<0.01)$, higher postoperative MSQH-EJD scores $(15.0$ vs. $11.0, \mathrm{P}<0.01)$ and greater postoperative ejaculation improvement ( $2.4 v s$. $0.5, \mathrm{P}=0.09)$ than patients reported as dissatisfied. Conversely, dissatisfied men were more likely to complain about alterations in sexual frequency $(52 \%$ vs. $24 \%, \mathrm{P}<0.01)$, new penile curvature ( $35 \%$ vs. $17 \%, \mathrm{P}<0.02)$, alterations in penile length $(48 \%$ vs. $32 \%, \mathrm{P}<0.02)$, decreased penile sensitivity (36\% vs. $20 \%, \mathrm{P}<0.02)$ and cold glans during erection $(12 \% v$ s. $3 \%, \mathrm{P}<0.01)$ compared to men who rated themselves as satisfied. Persistent urinary symptoms, genitourinary pain and alterations in postoperative sexual function had the greatest effect on postoperative dissatisfaction. Notably, men reporting dissatisfaction had fourfold greater odds of experiencing a decrease in sexual activity (OR 4.36).

In a prospective series of 94 urethroplasty patients, 
Table 5 Summary of genital sensitivity disorders and glans tumescence after urethroplasty

\begin{tabular}{|c|c|c|c|c|c|c|}
\hline Author, year & Study type & $\mathrm{N}$ & $\begin{array}{l}\text { Stricture } \\
\text { location }\end{array}$ & Intervention & $\begin{array}{l}\text { Follow-up } \\
\text { (months) }\end{array}$ & Results \\
\hline $\begin{array}{l}\text { Barbagli et al., } \\
2007,(29)\end{array}$ & Retrospective & $60 / 153^{* *}$ & Bulbar & $\begin{array}{l}\text { Anastomotic } \\
\text { urethroplasty }\end{array}$ & 68 & $\begin{array}{l}1.6 \% \text { cold glans; } 11.6 \% \text { decreased glans } \\
\text { tumescence; } 18.3 \% \text { decreased sensitivity of } \\
\text { the glans or distal penile shaft }\end{array}$ \\
\hline $\begin{array}{l}\text { Palminteri et } \\
\text { al., 2011, (34) }\end{array}$ & Retrospective & $49 / 73^{\star}$ & Bulbar & $\begin{array}{l}\text { 2-sided bulbar } \\
\text { urethroplasty with BMG }\end{array}$ & 12 & $2 \%$ decreased glans sensitivity \\
\hline $\begin{array}{l}\text { Patel et al., } \\
2015,(27)\end{array}$ & Retrospective & $22 / 33^{\star \star}$ & Penile & BMG staged repair & $\begin{array}{l}6.3 \text { (after } \\
\text { 2nd stage) }\end{array}$ & $\begin{array}{l}36 \% \text { decreased penile sensitivity, } 9 \% \\
\text { increased penile sensitivity, } 55 \% \text { no } \\
\text { sensitivity changes }\end{array}$ \\
\hline $\begin{array}{l}\text { Beysens et al., } \\
2015,(37)\end{array}$ & Prospective & $\begin{array}{l}45 \text { at } 6 \\
\text { weeks; } 25 \text { at } \\
6 \text { months }\end{array}$ & Bulbar & $\begin{array}{l}\mathrm{AU}[31] \text {; free graft } \\
\text { urethroplasty [16] [12 } \\
\text { prepuce, } 4 \text { BMG] }\end{array}$ & 23.3 & $\begin{array}{l}62.2 \% \text { and } 52 \% \text { reported altered genital } \\
\text { sensitivity at } 6 \text { weeks and } 6 \text { months, } \\
\text { respectively. No significant differences } \\
\text { between groups. } 1 \text { patient (AU group) had } \\
\text { cold glans at } 6 \text { weeks. No cold glans was } \\
\text { reported at } 6 \text { months }\end{array}$ \\
\hline $\begin{array}{l}\text { Spencer et al., } \\
2017,(35)\end{array}$ & Retrospective & $42 / 73$ & Panurethral & $\begin{array}{l}\text { One-sided urethral } \\
\text { dissection, penile } \\
\text { invagination, dorsal } \\
\text { BMG onlay }\end{array}$ & 44 & $10 \%$ decreased penile sensitivity \\
\hline
\end{tabular}

*, sexually active; **, completed the questionnaires. AU, anastomotic urethroplasty; BMG, buccal mucosa graft; DBG, dorsal buccal grafting.

evaluated preoperatively and after 6 months postoperatively using IPSS, IIEF, and an urethroplasty quality of life survey, Maciejewski et al. (44) found that only penile shortening (OR 2.26) and chordee (OR 2.26) retained statistical significance as independent predictors of patient satisfaction in multivariate analysis. These complications following urethroplasty cause significant unexpected patient distress, leading to a reduction in the overall satisfaction score which further emphasizes the need for standardized questionnaires that consider patient-reported sexual function and genital condition for evaluation of urethroplasty outcomes.

In a similar way, Kessler et al. (36) in 2002 reported that severe penile curvature, marked penile shortening and severe erection deterioration greatly influenced patient's dissatisfaction with surgical outcomes. They suggested that outcomes after urethral surgery should not only be assessed by objective criteria such as urinary peak flow, post void residual urine, or radiological appearance, but also through subjective measures, like post void dribbling, milking of urethra, cosmetic appearance, erection deterioration, penile curvature and shortening and impairment of sexual life. This was in line with their finding that only $78 \%$ of patients in whom urethroplasty was considered successful were satisfied with the outcome of urethral surgery. 


\section{Conclusions}

It is well proven that anterior urethral surgery can have consequences over sexual function, affecting erection, ejaculation and/or genital sensitivity. Sexual health is an important issue for patients undergoing urethral reconstruction. Deterioration of sexual function may cause postoperative dissatisfaction, even when a patent urethra is achieved. Penile urethra interventions, long panurethral urethroplasties, and revision surgeries pose the greater risks.

The functional benefit of non-transecting approach and grafting techniques in bulbar urethra remain controversial when compared with EPA. Prospective well designed and conducted studies are required to clarify those aspects.

Pre- and post-operative evaluation of sexual function using validated tools is of outmost importance. It can provide objective information for adequate preoperative counselling, outcome evaluation and early complication detection.

\section{Acknowledgments}

Funding: None.

\section{Footnote}

Reporting Checklist: The authors have completed the PRISMA reporting checklist. Available at: http://dx.doi. org/10.21037/tau-20-1307

Peer Review File: Available at http://dx.doi.org/10.21037/ tau-20-1307

Provenance and Peer Review: This article was commissioned by the Guest Editors (Francisco E. Martins and Tobias S. Köhler) for the series "Controversies and Considerations of Penile Surgery" published in Translational Andrology and Urology. The article has undergone external peer review.

Conflicts of Interest: The authors have completed the ICMJE uniform disclosure form (available at http://dx.doi. org/10.21037/tau-20-1307). The series "Controversies and Considerations of Penile Surgery" was commissioned by the editorial office without any funding or sponsorship. The authors have no other conflicts of interest to declare.

Ethical Statement: The authors are accountable for all aspects of the work in ensuring that questions related to the accuracy or integrity of any part of the work are appropriately investigated and resolved.

Open Access Statement: This is an Open Access article distributed in accordance with the Creative Commons Attribution-NonCommercial-NoDerivs 4.0 International License (CC BY-NC-ND 4.0), which permits the noncommercial replication and distribution of the article with the strict proviso that no changes or edits are made and the original work is properly cited (including links to both the formal publication through the relevant DOI and the license). See: https://creativecommons.org/licenses/by-nc-nd/4.0/.

\section{References}

1. Santucci RA, Joyce GF, Wise M. Male Urethral Stricture Disease. The Journal of Urology 2007;177:1667-74.

2. Palminteri E, Berdondini E, Verze P, et al. Contemporary urethral stricture characteristics in the developed world. Urology 2013;81:191-6.

3. Lumen N, Hoebeke P, Willemsen P, et al. Etiology of urethral stricture disease in the 21st century. J Urol 2009;182:983-7.

4. Levy M, Gor RA, Vanni AJ, et al. The Impact of Age on Urethroplasty Success. Urology 2017;107:232-8.

5. Erickson BA, Ghareeb GM. Definition of Successful Treatment and Optimal Follow-up after Urethral Reconstruction for Urethral Stricture Disease. Urol Clin North Am 2017;44:1-9.

6. Moher D, Liberati A, Tetzlaff J, et al. Preferred Reporting Items for Systematic Reviews and Meta-Analyses: The PRISMA Statement. PLOS Medicine 2009;6:e1000097.

7. Mundy AR. Results and complications of urethroplasty and its future. Br J Urol 1993;71:322-5.

8. Blaschko SD, Sanford MT, Cinman NM, et al. De novo erectile dysfunction after anterior urethroplasty: a systematic review and meta-analysis. BJU Int 2013;112:655-63.

9. Rosen RC, Riley A, Wagner G, et al. The international index of erectile function (IIEF): a multidimensional scale for assessment of erectile dysfunction. Urology 1997;49:822-30.

10. O'Leary MP, Fowler FJ, Lenderking WR, et al. A brief male sexual function inventory for urology. Urology 1995;46:697-706.

11. Rosen RC, Catania J, Pollack L, et al. Male Sexual Health Questionnaire (MSHQ): scale development and psychometric validation. Urology 2004;64:777-82.

12. Palminteri E, Berdondini E, De Nunzio C, et al. The 
impact of ventral oral graft bulbar urethroplasty on sexual life. Urology 2013;81:891-8.

13. Lue TF, Zeineh SJ, Schmidt RA, et al. Neuroanatomy of penile erection: its relevance to iatrogenic impotence. J Urol 1984;131:273-80.

14. Yucel S, Baskin LS. Neuroanatomy of the male urethra and perineum. BJU Int 2003;92:624-30.

15. Yucel S, Baskin LS. Identification of communicating branches among the dorsal, perineal and cavernous nerves of the penis. J Urol 2003;170:153-8.

16. Coursey JW, Morey AF, McAninch JW, et al. Erectile function after anterior urethroplasty. J Urol 2001;166:2273-6.

17. Erickson BA, Wysock JS, McVary KT, et al. Erectile function, sexual drive, and ejaculatory function after reconstructive surgery for anterior urethral stricture disease. BJU Int 2007;99:607-11.

18. Anger JT, Sherman ND, Webster GD. The effect of bulbar urethroplasty on erectile function. J Urol 2007;178:1009-11; discussion 11.

19. Dogra PN, Saini AK, Seth A. Erectile dysfunction after anterior urethroplasty: a prospective analysis of incidence and probability of recovery--single-center experience. Urology 2011;78:78-81.

20. DeLong J, Buckley J. Patient-reported outcomes combined with objective data to evaluate outcomes after urethral reconstruction. Urology 2013;81:432-6.

21. Chapman DW, Cotter K, Johnsen NV, et al. Nontransecting Techniques Reduce Sexual Dysfunction after Anastomotic Bulbar Urethroplasty: Results of a Multi-Institutional Comparative Analysis. J Urol 2019;201:364-70.

22. Haines T, Rourke KF. The effect of urethral transection on erectile function after anterior urethroplasty. World J Urol 2017;35:839-45.

23. Xie H, Xu YM, Xu XL, et al. Evaluation of erectile function after urethral reconstruction: a prospective study. Asian J Androl 2009;11:209-14.

24. Erickson BA, Granieri MA, Meeks JJ, et al. Prospective analysis of erectile dysfunction after anterior urethroplasty: incidence and recovery of function. J Urol 2010;183:657-61.

25. Pfalzgraf D, Kluth L, Reiss P, et al. Redo-urethroplasty: comparison of early functional results and quality of life in penile and bulbar strictures. World J Urol 2014;32:1191-7.

26. Shakir NA, Fuchs JS, Haney N, et al. Excision and Primary Anastomosis Reconstruction for Traumatic Strictures of the Pendulous Urethra. Urology 2019;125:234-8.

27. Patel DP, Elliott SP, Voelzke BB, et al. Patient-Reported Sexual Function After Staged Penile Urethroplasty.
Urology 2015;86:395-400.

28. Morey AF, Kizer WS. Proximal bulbar urethroplasty via extended anastomotic approach--what are the limits? J Urol 2006;175:2145-9; discussion 9.

29. Barbagli G, De Angelis M, Romano G, et al. Long-term followup of bulbar end-to-end anastomosis: a retrospective analysis of 153 patients in a single center experience. J Urol 2007;178:2470-3.

30. D'hulst P, Floyd MS Jr, Castiglione F, et al. Excision and Primary Anastomosis for Bulbar Urethral Strictures Improves Functional Outcomes and Quality of Life: A Prospective Analysis from a Single Centre. Biomed Res Int 2019;2019:7826085.

31. Jordan GH, Eltahawy EA, Virasoro R. The technique of vessel sparing excision and primary anastomosis for proximal bulbous urethral reconstruction. J Urol 2007;177:1799-802.

32. Andrich DE, Mundy AR. Non-transecting anastomotic bulbar urethroplasty: a preliminary report. BJU Int 2012;109:1090-4.

33. Lumen N, Spiers S, De Backer S, et al. Assessment of the short-term functional outcome after urethroplasty: a prospective analysis. Int Braz J Urol 2011;37:712-8.

34. Palminteri E, Berdondini E, Shokeir AA, et al. Two-sided bulbar urethroplasty using dorsal plus ventral oral graft: urinary and sexual outcomes of a new technique. J Urol 2011;185:1766-71.

35. Spencer J, Blakely S, Daugherty M, et al. Clinical and Patient-reported Outcomes of 1-sided Anterior Urethroplasty for Long-segment or Panurethral Strictures. Urology 2018;111:208-13.

36. Kessler TM, Fisch M, Heitz M, et al. Patient satisfaction with the outcome of surgery for urethral stricture. J Urol 2002;167:2507-11.

37. Beysens M, Palminteri E, Oosterlinck W, et al. Anastomotic Repair versus Free Graft Urethroplasty for Bulbar Strictures: A Focus on the Impact on Sexual Function. Adv Urol 2015;2015:912438.

38. Furr JR, Wisenbaugh ES, Gelman J. Urinary and Sexual Outcomes Following Bulbar Urethroplasty-An Analysis of 2 Common Approaches. Urology 2019;130:162-6.

39. Raber M, Naspro R, Scapaticci E, et al. Dorsal onlay graft urethroplasty using penile skin or buccal mucosa for repair of bulbar urethral stricture: results of a prospective single center study. Eur Urol 2005;48:1013-7.

40. Lumen N, Hoebeke P, Oosterlinck W. Ventral longitudinal stricturotomy and transversal closure: the Heineke-Mikulicz principle in urethroplasty. Urology 
2010;76:1478-82.

41. Johnson EK, Latini JM. The impact of urethroplasty on voiding symptoms and sexual function. Urology 2011;78:198-201.

42. Levine MA, Kinnaird AS, Rourke KF. Revision urethroplasty success is comparable to primary urethroplasty: a comparative analysis. Urology 2014;84:928-32; quiz 32-3.

43. Palminteri E, Berdondini E, Florio M, et al. Two-sided urethra-sparing reconstruction combining dorsal preputial skin plus ventral buccal mucosa grafts for tight bulbar strictures. Int J Urol 2015;22:861-6.

44. Maciejewski CC, Haines T, Rourke KF. Chordee and Penile Shortening Rather Than Voiding Function Are Associated With Patient Dissatisfaction After Urethroplasty. Urology 2017;103:234-9.

45. Önol FF, Bindayi A, Tahra A, et al. Turkish validation of the urethral stricture surgery specific patient-reported outcome measure (USS-PROM) with supplemental assessment of erectile function and morbidity due to oral graft harvesting. Neurourol Urodyn 2017;36:2089-95.

46. Verla W, Waterloos $M$, Waterschoot $M$, et al. VeSpAR trial: a randomized controlled trial comparing vesselsparing anastomotic repair and transecting anastomotic repair in isolated short bulbar urethral strictures. Trials 2020;21:782.

47. Erickson BA, Granieri MA, Meeks JJ, et al. Prospective analysis of ejaculatory function after anterior urethral reconstruction. J Urol 2010;184:238-42.

48. Barbagli G, De Stefani S, Annino F, et al. Muscle- and

Cite this article as: Calleja Hermosa $\mathrm{P}$, Campos-Juanatey F, Varea Malo R, Correas Gómez MÁ, Gutiérrez Baños JL; Trauma and Reconstructive Urology Working Party of the European Association of Urology Young Academic Urologists. Sexual function after anterior urethroplasty: a systematic review. Transl Androl Urol 2021;10(6):2554-2573. doi: 10.21037/tau-201307 nerve-sparing bulbar urethroplasty: a new technique. Eur Urol 2008;54:335-43.

49. Fredrick A, Erickson BA, Stensland K, et al. Functional Effects of Bulbospongiosus Muscle Sparing on Ejaculatory Function and Post-Void Dribbling after Bulbar Urethroplasty. J Urol 2017;197:738-43.

50. Dubey D, Sehgal A, Srivastava A, et al. Buccal mucosal urethroplasty for balanitis xerotica obliterans related urethral strictures: the outcome of 1 and 2-stage techniques. J Urol 2005;173:463-6.

51. Dubey D, Kumar A, Bansal P, et al. Substitution urethroplasty for anterior urethral strictures: a critical appraisal of various techniques. BJU Int 2003;91:215-8.

52. Sharma V, Kumar S, Mandal AK, et al. A study on sexual function of men with anterior urethral stricture before and after treatment. Urol Int 2011;87:341-5.

53. Kulkarni S, Barbagli G, Sansalone S, et al. One-sided anterior urethroplasty: a new dorsal onlay graft technique. BJU Int 2009;104:1150-5.

54. Levine LA, Strom KH, Lux MM. Buccal mucosa graft urethroplasty for anterior urethral stricture repair: evaluation of the impact of stricture location and lichen sclerosus on surgical outcome. J Urol 2007;178:2011-5.

55. Al-Qudah HS, Santucci R A. Extended complications of urethroplasty. Int Braz J Urol 2005;31:315-23; discussion 24-5.

56. Bertrand LA, Voelzke BB, Elliott SP, et al. Measuring and Predicting Patient Dissatisfaction after Anterior Urethroplasty Using Patient Reported Outcomes Measures. J Urol 2016;196:453-61. 